\title{
CLEC-based Study of Tense Errors in Chinese EFL Learners' Writings
}

\author{
Juan $\mathrm{Liu}^{1, *}$ \\ ${ }^{1}$ Inner Mongolia University of Finance and Economics, Hohhot, China \\ *Correspondence: Inner Mongolia University of Finance and Economics, Hohhot, China. E-mail: \\ 13664884711@163.com
}

Received: October 13, 2012 Accepted: November 3, $2012 \quad$ Online Published: December 2, 2012

doi:10.5430/wjel.v2n4p11 URL: http://dx.doi.org/10.5430/wjel.v2n4p11

\begin{abstract}
In this dissertation, we conduct error analysis of the learner's writing competence based on Chinese Learner English Corpus. According to the data from CLEC, the verb error heads the list among the tagged errors of different parts of speech. To address this issue, we set the following as research question of this study: 1 . Which kind of error occurs most frequently among the tense errors in the sample writings in CLEC? 2. Are there any differences in the tense errors students committed within limited time and unlimited time? The writer has conducted an empirical Error Analysis by integrating error statistics and the corpus-based approach. Specific data for analysis have been obtained from CLEC and compositions written by the freshmen of non-English majors in Inner Mongolia Finance and Economics College. After a thorough analysis, we get the following major findings:

1. On the whole, most of the sixteen categories of misuse of tenses are widespread among the five corpora. Although the students of each corpus have different language proficiencies, present tense and past tense are the two most frequently misused tenses in every corpus, while all kinds of future tenses except future tense itself and all kinds of past future tenses except past future tense itself are the least frequently misused tenses in each corpus.

2. Generally speaking, the sixteen categories of tense errors distribute more evenly in free writings and the error rates of the same tense are different in CLEC and in free writings, which shows that the time limit can indeed affect the students' performance on tense errors.
\end{abstract}

3. The causes leading to verb errors are mother tongue influence, target language influence and cognitive factors.

Keywords: Error analysis; Chinese Learner English Corpus; Verb error; Free writing; Misuse of tense

\section{Introduction}

In English writings, verb is the most active part in sentence for expressing an action, an occurrence, or a state of being. F.R.Palmer (1965: 5) suggests that "learning a language is to a very large degree learning how to operate the verbal forms of that language." In various languages, verb is inflected for tense, for voice, for mood, or for aspect. Since there are no verb inflections in Chinese, some linguists agree that there are no tenses in Chinese (Lyons, 1977: 23). In view of the non-equivalence in Chinese and in English, it is not surprising that the expression of time through verbs is one of the most puzzling and problematic domains in Second Language Acquisition (SLA). Gui Shichun also finds that non-native speakers are strongly influenced by use of tenses of their first language when they are trying to understand temporality of the second language.

Matching with the development of study of tense, Error analysis (EA) is maturing both in theory and in technique nowadays. The rise of Error analysis, on the one hand, lies in behaviorist learning theory's inadequacies in explaining the nature of SLA. On the other hand, it is creditable to the work of mentalist Corder, "The Significance of Learners' Errors". Unlike the behaviorist learning theory, the mentalist language acquisition theory lays great emphasis on the importance of the learner's innate aptitude at the expense of environmental factors (Brooks, 1960: 122). Within the framework of this theory, each learner is credited with what Chomsky calls a "language acquisition device" (LAD) which directs the process of language acquisition. The device contains information about the possible forms that the grammar of any language can take.

Researchers in the Chomsky consider that children (possibly adults as well) possess the knowledge of abstract 
language principles which serve as a basis for acquiring the rules of a particular language. Some researchers focus their attentions on both children and adults' SLA, such as Dulay and Burt (1974), Corder (1967), Richards (1974). In China, scholars have begun to introduce EA theory and its basis of interlanguage since 1980s.

All in all, EA contributes much to Second Language Acquisition (SLA) research. Perhaps the most important contribution is that EA helps researchers realize that errors are not something to be avoided but are inevitable features of the learning process. It is commonly employed by teachers, which enables them to find the general and specific characteristics of learners' errors. Generally, the procedure for error analysis is as follows:

1) Selection of a corpus of language

2) Identification of errors in the corpus

3) Description of the errors identified

4) Explanation of the causes of the errors

5) Evaluation of error gravity and ranking of the errors (Corder, 1974)

The starting point for error analysis (Step 1) is to construct a corpus of interlanguage, particularly, what samples of learner errors are used for analysis and how these samples are collected. In this dissertation, we start error analysis by choosing CLEC as the established corpus and by collecting 130 free writings produced by L2 learners as the other corpus. After the corpus has been constructed, the errors have to be identified, which is typically Step 2 does. An important methodological consideration in need of attention is to distinguish errors and mistakes, which will be described in the following section. In Step 3, the description of errors involves a comparison of the error frequency in CLEC with that in free writing. Step 4 is to try to explain the source of the errors, i.e. accounting for why they are made. Generally speaking, Step 5 is usually excluded in many EA studies. In this dissertation, a much more detailed description of errors will be presented in the fourth part and the last step will not be mentioned here.

As Dulay and Burt (1974) put, "You cannot learn without goofing." Error seems to be an unavoidable phenomenon in the process of learning a foreign language. The purpose of the present study is to investigate the tense errors in Chinese students' English compositions. After the errors were detected, they were classified into different categories and the most frequently occurring errors were figured out. We hope that the study might throw new lights on the L2 teaching and learning. Based on EA theory, we set the following as research question of this study:

1) Which kind of error occurs most frequently among the tense errors in the sample writings in CLEC?

2) Are there any differences in the tense errors students committed within limited time and unlimited time?

\section{Methodology}

\subsection{Chinese Learner English Corpus (CLEC)}

In this paper, we conduct error analysis of the learner's writing competence based on Chinese Learner English Corpus (CLEC). The Chinese Learner English Corpus (CLEC) has been constructed by joint efforts of Guangdong Foreign Studies University, Shanghai Jiaotong University and some other universities in China under the leadership of Prof. Gui Shichun and Prof. Yang Huizhong, which was one of the important projects in the Ninth Five-Year Plan of the National Foundation of Social Sciences and Humanities and finally got published by Shanghai Foreign Language Education Press in 2003. This corpus has collected more than 1000,000 words from the interlanguage production of Chinese learners from different backgrounds and at different proficiency levels, which can be further divided into five sub-corpora: ST2, ST3, ST4, ST5 and ST6. Each sub-corpus is a collection of written compositions by Chinese learners at different proficiency levels. The raw token (total number of words) distributions of the five sub-corpora are as follows: 
Table 1: The Basic Information of the Selected Subjects

\begin{tabular}{lll}
\hline Sub-corpus & Proficiency & Total words \\
\hline ST2 & Senior high school students & 251353 words \\
ST3 & Freshmen and sophomores of non-English majors, and most of & 232575 words \\
& whom will take CET4. & \\
ST4 & Juniors and seniors of non-English majors, and most of whom & 241979 words \\
& will take CET6 & \\
ST5 & Freshmen and sophomores of English majors & 238020 words \\
ST6 & Juniors and seniors of English majors & 244025 words \\
\hline
\end{tabular}

CLEC contains frequency list, and is in error tagged text version, by which all language errors are categorized with two tiers. For instance, "vp" (the first tier) refers to the verb phrase error; "vp1" (the second tier) stands for verb phrase error in pattern; "vp2" stands for set phrase errors and "vp3" indicates the errors of disagreement with its subject (noun or pronoun), etc. In the samples, error tags are inserted in where errors occur and are bracketed in square brackets. For example, In the past, people are [vp6,4-] kind to each other... The square brackets and their enclosed letters and numbers such as [vp6], [vp1] are error tags, representing different types of errors. Vp6 is an error tag of tense and it belongs to a verb phrase error. "4-" shows the scope of error occurrence; " 4 " means there are 4 words before the error that are needed for determining the occurrence of the error, and the "_" shows the position of the error. On the whole, there are 61 types of errors identified in this corpus running across sentence, phrase and word level (See Appendix I).

\subsection{Procedure of the Research}

The research will follow the following procedure:

1) Searching from the five sub-corpora of CLEC, all the tags related to verb errors were extracted by running the MYFINDER program. Then re-classification and re-categorization of VP6 errors according to Bo Bing's tense model in ST3 were made. For example, the following is a part of the full concordance with the head VP6 in the middle and five words on either side of it as the context.

[fm1,-], we must have [ vp6 -s] known something about it.

morning at 6:00, i begin [ vp6 -s] running, and soon my

my performance of running is [ vp6 -s] improved [sn6,s-] i succeed.

again and again, we mastered [vp6 -s] it and make a

practice what [wd3,1-] we took [ vp6 -s] makes perfect in the

perfectly, so [wd5,-s] we cooked [ vp6 -s] a very good dinner.

old in 1990. it increased [ vp6 s-] [cc3,1-3] 20 years old

however, in 1990 it is [ vp6 3-1] 10\%. it decreased [vp1,-1]

and infant mortaility [fm1,-] are [vp6 s-] changed [vp7,s-] very much

- $\quad$ hope the medicine developed [ vp6 s-] rapily [fm1,-] and the

gains in developing countries make [ vp6 -4] a new step tomorrow.

in their next generation are [ vp6 -s-] more strong [aj3,1-] ,

[fm1,-] has [vp3,s-] been changed [ vp6 s-] since [wd3,s-] 1960 to

2) Next, analysis of the tense errors would be made and then the most frequently misused tense errors would be highlighted.

3) Simultaneously, 130 freshmen of Inner Mongolia Finance and Economics College in China were chosen as subjects. Most of the subjects were going to take part in the CET4 in December, 2011, and several of them had acquired the certificate of CET4. Those subjects were asked to write compositions on the same topic as CET4, 
but without time limit. The titles are "Getting to Know the World Outside the Campus" and "My View on Job-Hopping", one of which can be selected and developed into a composition with 120-150 words out of their own wills.

4) After all the subjects turned in their compositions, the author and two other English teachers went through all the compositions three times and tagged tense errors found in them according to Professor Gui' s category and Bo Bing' s tense model, namely, misuse of simple present tense, misuse of present progressive tense, misuse of present perfect tense, misuse of present perfect progressive tense, misuse of simple past tense, misuse of past progressive tense, misuse of past perfect tense, misuse of past perfect progressive tense, misuse of future tense, misuse of future progressive tense, misuse of future perfect tense, misuse of future perfect progressive tense, misuse of past future tense, misuse of past future perfect tense, misuse of past future progressive tense and misuse of past future perfect progressive tense.

5) Afterwards, comparisons were made between the results we got in CLEC and in free writings.

\section{Data Presentation and Discussion}

\subsection{Presentation of the Result Got from CLEC}

\subsubsection{VP6: Errors in Tense}

By using the software, we have found that vp6 has the largest share in verb errors, with a total of 2971 marked errors. The number of vp6 in each corpus is listed below:

Table 2: The Frequency of VP6 in the Five Sub-corpora

\begin{tabular}{lllllll}
\hline Error-tags & ST2 & ST3 & ST4 & ST5 & ST6 & Total \\
\hline VP6 & 1465 & 414 & 377 & 452 & 263 & 2971 \\
VP6(\%) & $45.36 \%$ & $17.64 \%$ & $13.78 \%$ & $33.14 \%$ & $21.26 \%$ & --- \\
TTL VP ERRS & 3230 & 2347 & 2735 & 1364 & 1237 & 10913 \\
\hline
\end{tabular}

From the table, we can see high frequencies of vp6 distribute in CLEC and in each corpus, especially in ST2, with the percentage of $45.36 \%$ in all the verb errors of ST2, but these are just the initial results of the vp6 errors found by the computer. After analyzing and categorizing these data, we find that some cases and statistics involving vp6 are not exactly accurate, which need to re-analyze manually in order to guarantee the reliable results of the present study. More specifically, in some places, tagged errors of vp6 are not misused at all or some even should not fall into the category of tense. For example, such error as "have enable [vp6,-]" is mistakenly regarded as error of past participle in VP6. Take another case "misspelling of tense form" for example, as misspelling should not be marked for tense, we sort out the similar unnecessary markers of tense. Therefore, we have recalculated the number of misuse of tenses tagged vp6 in the five sub-corpora after eliminating the questionable vp6. The recalculation of misuse of tenses is listed as follows (See Table 3):

Table 3: Reclassification of Misuse of Tenses in the Five Sub-corpora

\begin{tabular}{lllllll}
\hline Corpus & ST2 & ST3 & ST4 & ST5 & ST6 & Total \\
\hline VP6 & 1405 & 395 & 368 & 411 & 255 & 2834
\end{tabular}

The large numbers of tense errors occurring in the students' compositions are a good proof that tense is universally accepted to be difficult especially for Chinese learners. Because of the highest error rate, we make one step closer to the tense error in order to find out which tense puzzles the Chinese learners most.

\subsubsection{The Most Frequent Tense Error}

Bo Bing (2003) adopts the sixteen - tense conception in A New English Grammar and puts forward detailed explanations, which are directional and helpful for Chinese learners to put the theory into practice. Based on Bo Bing' theory, the present study distinguishes 16 English tenses. Accordingly, we classify the vp6 errors into 16 categories. Since these 16 sub-categories are not classified in CLEC, they are retagged by the author manually. Through re-analyzing and categorizing the VP6 errors, we draw the following table. 
Table 4: The Frequency of Sixteen - Tense Errors

\begin{tabular}{lllllll}
\hline Tense errors & ST2 & ST3 & ST4 & ST5 & ST6 & Total \\
\hline Misuse of simple present tense & 835 & 173 & 96 & 218 & 84 & 1406 \\
Misuse of present progressive tense & 30 & 5 & 4 & 7 & 1 & 47 \\
Misuse of present perfect tense & 88 & 16 & 9 & 14 & 8 & 135 \\
Misuse of present perfect progressive tense & 18 & 3 & 4 & 12 & 2 & 39 \\
Misuse of simple past tense & 312 & 162 & 220 & 113 & 112 & 919 \\
Misuse of past progressive tense & 20 & 5 & 2 & 3 & 2 & 32 \\
Misuse of past perfect tense & 73 & 12 & 15 & 17 & 30 & 147 \\
Misuse of past perfect progressive tense & 5 & 1 & 2 & 3 & 4 & 15 \\
Misuse of future tense & 18 & 6 & 5 & 8 & 2 & 39 \\
Misuse of future progressive tense & 0 & 0 & 0 & 1 & 2 & 3 \\
Misuse of future perfect tense & 0 & 0 & 1 & 0 & 0 & 1 \\
Misuse of future perfect progressive tense & 0 & 0 & 0 & 0 & 0 & 0 \\
Misuse of past future tense & 4 & 11 & 10 & 12 & 6 & 43 \\
Misuse of past future perfect tense & 2 & 1 & 0 & 3 & 2 & 8 \\
Misuse of past future progressive tense & 0 & 0 & 0 & 0 & 0 & 0 \\
Misuse of past future perfect progressive tense & 0 & 0 & 0 & 0 & 0 & 0 \\
Total & 1405 & 395 & 368 & 411 & 255 & 2834 \\
\hline
\end{tabular}

In order to make further analysis across the corpus, normalization is also made. The procedures of normalization are as follows: firstly, we try to get the proportion between the frequency of each error and the total word tokens in this corpus; secondly, we multiply the former result by 200,000 , supposing there are 200,000 words in each sub-corpus on average, and then we can get the figure of the normalized frequency counts. For example, misuse of VP6 appears 1465 times in ST2, then 1465/251353 (total tokens of ST2) $\times 200,000=1165.7$ (Gui Shichun, 2005: 9). The following is a normalized table about frequencies of 16 categories of misuse of tenses in each sub-corpus:

Table 5: Normalized Frequencies of Sixteen - Tense Errors

\begin{tabular}{lllllll}
\hline Tense errors & ST2 & ST3 & ST4 & ST5 & ST6 & Total \\
\hline Misuse of simple present tense & 664.4 & 148.8 & 79.3 & 183.2 & 68.8 & 1144.5 \\
Misuse of present progressive tense & 23.9 & 4.3 & 3.3 & 5.9 & 0.8 & 38.2 \\
Misuse of present perfect tense & 70.0 & 13.8 & 7.4 & 11.8 & 6.6 & 109.5 \\
Misuse of present perfect progressive tense & 14.3 & 2.6 & 3.3 & 10.1 & 1.6 & 31.9 \\
Misuse of simple past tense & 248.3 & 139.3 & 181.8 & 95.0 & 91.8 & 756.1 \\
Misuse of past progressive tense & 15.9 & 4.3 & 1.7 & 2.5 & 1.6 & 26.0 \\
Misuse of past perfect tense & 58.1 & 10.3 & 12.4 & 14.3 & 24.6 & 119.7 \\
Misuse of past perfect progressive tense & 4.0 & 0.9 & 1.7 & 2.5 & 3.3 & 12.3 \\
Misuse of future tense & 14.3 & 5.2 & 4.1 & 6.7 & 1.6 & 32.0 \\
Misuse of future progressive tense & 0.0 & 0.0 & 0.0 & 0.8 & 1.6 & 2.5 \\
Misuse of future perfect tense & 0.0 & 0.0 & 0.8 & 0.0 & 0.0 & 0.8 \\
Misuse of future perfect progressive tense & 0.0 & 0.0 & 0.0 & 0.0 & 0.0 & 0.0 \\
Misuse of past future tense & 3.2 & 9.5 & 8.3 & 10.1 & 4.9 & 35.9 \\
Misuse of past future perfect tense & 1.6 & 0.9 & 0.0 & 2.5 & 1.6 & 6.6 \\
Misuse of past future progressive tense & 0.0 & 0.0 & 0.0 & 0.0 & 0.0 & 0.0 \\
Misuse of past future perfect progressive & 0.0 & 0.0 & 0.0 & 0.0 & 0.0 & 0.0 \\
tense & & & & & & \\
Total & 1117.9 & 339.7 & 304.2 & 345.3 & 209.0 & 2316.1 \\
\hline
\end{tabular}

For the sixteen categories of tenses in the five corpora, misuse of simple present tense far outnumbers other tenses (1144.5), followed by misuse of simple past tense (756.1); the third most frequently misused tense is past perfect tense (119.7), not much higher than the frequency of misuse of present perfect tense (109.5). Present 
progressive tense, present perfect progressive tense, past progressive tense, future tense and past future tense are misused relatively less frequently compared with the tenses just mentioned while past perfect progressive tense and past future perfect tense are misused even less. Misuse of future perfect progressive tense, past future progressive tense and past future perfect progressive tense are not found in any of the corpus.

From the above table, we can get the following results:

1. On the whole, sixteen categories of misuse of tenses are widespread among the five corpora. Through careful observation of the result, we found ST2 (senior high school students) far outweigh the other groups in misuse of tenses while ST6 (seniors majoring in English) misuses tenses at the lowest frequency. The frequencies of misuse of tenses in ST3 and ST4 (non-English major college students) are similar to each other whereas that in ST5 (English-major college students Grade one) is a bit higher. Although the students of each corpus have different language proficiencies, simple present tense and simple past tense are the two most frequently misused tenses in every corpus, while all kinds of future tenses except future tense itself and all kinds of past future tenses except past future tense itself are the least frequently misused tenses in each corpus.

2. In the sub-corpus ST2, the most frequently misused tense is simple present tense (664.4); the second most frequently misused tense is simple past tense (248.3) which is followed by present perfect tense (70.0), past perfect tense (58.1), present progressive tense (23.9) and past progressive tense (15.9), while misuse of present perfect progressive tense (14.3) and future tense (14.3) occur much less frequently in this corpus. There are no misuses of future progressive tense, future perfect tense, future perfect progressive tense, past future progressive tense and past future perfect progressive tense in ST2.

3. In the sub-corpus ST3, the first two categories of misuse of tenses which occur most frequently are: misuse of simple present tense (148.8), misuse of simple past tense (139.3); the third most frequently misused tense is misuse of present perfect tense (13.8) which is followed closely by misuse of past perfect tense (10.3), past future tense (9.5). Misuse of future tense (5.2), misuse of past progressive tense (4.3), misuse of present progressive tense (4.3) and misuse of present perfect progressive tense (2.6) happen less frequently with close frequency figures, and misuse of past future perfect tense (0.9) and misuse of past perfect progressive tense (0.9) happen even less. There are no misuses of future progressive tense, future perfect tense, future perfect progressive tense, past future progressive tense and past future perfect progressive tense in ST3.

4. In the sub-corpus ST4, misuse of simple past tense (181.8) amounts to the largest part of the total misuse of tenses (304.2), more than double the frequency of misuse of simple present tense (79.3). Misuse of past perfect tense occupies the third largest frequency of the total misuse of tenses (12.4) and it is followed by misuse of present perfect tense (7.4) and past future tense (8.3) which frequency figures stand quite close to each other. Then the figures drop significantly in the misuse of future tense (4.1), present progressive tense (3.3), present perfect progressive tense (3.3), past progressive tense (1.7), past perfect progressive tense (1.7) and future perfect tense (0.8), and there are still no misuses of future progressive tense, future perfect progressive tense, past future perfect tense, past future progressive tense and past future perfect progressive tense.

5. In the sub-corpus ST5, misuse of simple present tense and simple past tense are the most frequently misused tenses, but the frequency of the latter (95.0) is only near half of the former (183.2). Past perfect tense (14.3) and present perfect tense (11.8) are the third and fourth most frequently misused tenses, while misuse of present perfect progressive tense (10.1) and misuse of past future tense (10.1) happen relatively less, which are followed by misuses of future tense (6.7), present progressive tense (5.9), past progressive tense (2.5), past perfect progressive tense (2.5), past future perfect tense (2.5) and future progressive tense (0.8). In ST5, future perfect tense, future perfect progressive tense, past future progressive tense and past future perfect progressive tense are not found.

6. In the sub-corpus ST6, the first five categories of misuse of tenses are: misuse of simple past tense (91.8), simple present tense (68.8), past perfect tense (24.6), misuse of present perfect tense (6.6) and past future tense (4.9). Misuse of present progressive tense, present perfect progressive tense, past progressive tense, past perfect progressive tense, future tense, future progressive tense and past future perfect tense happen less frequently with almost the same frequency figures, while there are no misuses of future perfect tense, future perfect progressive tense, past future progressive tense and past future perfect progressive tense in this corpus.

Among the five corpora, ST3 attract our special attention. Since the author herself has easy access to the students of IMFEC, who are also in the same grade and have the approximate language proficiencies as the students of ST3 in CLEC, the author tries to compare the tense errors the students made in the compositions of IMFEC's students and in CLEC. The compositions in CLEC are taken directly from CET4, which are limited in time and 
reference books, while the free writings of IMFEC's students are homework which is allowed to consult the reference books after class with no time limit comparatively, so the aim of this experiment is to test whether the time limit can affect the performance of students in tense errors or not under otherwise equal conditions.

\subsection{Analysis of the Free Writings}

In 2011, 130 freshmen of non-English majors in Inner Mongolia Finance and Economics College in China were chosen as subjects. Most of the subjects were going to take part in the CET4 in December, 2011, and several of them had got the certificate of CET4. They were asked to write compositions on the same topic as the title of CET4 selected in CLEC, but without time limit. The same topic guarantees similar words, proximate context to certain degree, and no time limit ensures that the students have free access to dictionaries, the Internet, magazines, textbook, etc. Furthermore, the students were told that their compositions would be given marks as mid-term examination scores, which made sure that every student took the homework seriously. After all students turned in their compositions one after another, correction and assessment work were done to see under otherwise equal conditions whether or not the frequency percentages of VP6 errors were the same as the statistical results of ST3 we had got in CLEC. The author and two other English teachers went through all the compositions three times and tagged tense errors found in them according to Professor Gui's standard and the categories of tenses. Similarly, we classify the vp6 errors into 16 categories. Through categorization and calculation, we draw the following conclusion:

Table 6: The Frequency of Tense Errors in Free Writings

\begin{tabular}{ll}
\hline Tense Errors & Frequency in Free Writing \\
\hline Misuse of simple present tense & 15 \\
Misuse of present progressive tense & 2 \\
Misuse of present perfect tense & 5 \\
Misuse of present perfect progressive tense & 4 \\
Misuse of simple past tense & 19 \\
Misuse of past progressive tense & 2 \\
Misuse of past perfect tense & 12 \\
Misuse of past perfect progressive tense & 3 \\
Misuse of future tense & 5 \\
Misuse of future progressive tense & 2 \\
Misuse of future perfect tense & 2 \\
Misuse of future perfect progressive tense & 0 \\
Misuse of past future tense & 3 \\
Misuse of past future perfect tense & 0 \\
Misuse of past future progressive tense & 1 \\
Misuse of past future perfect progressive tense & 0 \\
Total & 75 \\
\hline
\end{tabular}

In the free writings, the first two categories of misuse of tenses which occur most frequently are: misuse of simple past tense (19), misuse of simple present tense (15), and the third most frequently misused tense is past perfect tense (12) which is followed by misuse of present perfect tense (5) and future tense (5). Then the figures drop in the misuse of present progressive tense, present perfect progressive tense, past progressive tense, past perfect progressive tense, future progressive tense, future perfect tense, past future tense and past future progressive tense, whose frequency figures are close to each other. In the free writings, there are still no misuses of future perfect progressive tense, past future perfect tense and past future perfect progressive tense.

\subsection{Comparison of the Data from CLEC and Free Writings}

In this section, we will focus on the tense errors of ST3 in CLEC which is limited in time and the tense errors in free writings which are not limited comparatively in order to see whether the time limit affects the students' 
performance in terms of tense errors or not. Since the numbers of students of ST3 and IMFEC are different, the direct comparison of the errors is simple but thoughtless, whereas the comparison of error rate is more proper and precise which uses the specific tense error number divides the total of tense errors. Through statistics and calculation, we draw the following table:

Table 7: Comparison of Tense Errors in ST3 and in Free Writings

\begin{tabular}{|c|c|c|c|c|}
\hline Tense Errors & ST3 & $\begin{array}{l}\text { Percentage in } \\
\text { ST3 }\end{array}$ & Free Writing & $\begin{array}{l}\text { Percentage in Free } \\
\text { Writing }\end{array}$ \\
\hline $\begin{array}{l}\text { Misuse of simple simple present } \\
\text { tense }\end{array}$ & 173 & $44 \%$ & 17 & $23 \%$ \\
\hline $\begin{array}{l}\text { Misuse of present progressive } \\
\text { tense }\end{array}$ & 5 & $1 \%$ & 2 & $3 \%$ \\
\hline Misuse of present perfect tense & 16 & $4 \%$ & 3 & $4 \%$ \\
\hline $\begin{array}{l}\text { Misuse of present perfect } \\
\text { progressive tense }\end{array}$ & 3 & $1 \%$ & 4 & $5 \%$ \\
\hline Misuse of simple past tense & 162 & $41 \%$ & 22 & $29 \%$ \\
\hline Misuse of past progressive tense & 5 & $1 \%$ & 1 & $1 \%$ \\
\hline Misuse of past perfect tense & 12 & $3 \%$ & 13 & $17 \%$ \\
\hline $\begin{array}{l}\text { Misuse of past perfect progressive } \\
\text { tense }\end{array}$ & 1 & $0 \%$ & 3 & $4 \%$ \\
\hline Misuse of future tense & 6 & $2 \%$ & 2 & $3 \%$ \\
\hline Misuse of future progressive tense & 0 & $0 \%$ & 2 & $3 \%$ \\
\hline Misuse of future perfect tense & 0 & $0 \%$ & 2 & $3 \%$ \\
\hline $\begin{array}{l}\text { Misuse of future perfect } \\
\text { progressive tense }\end{array}$ & 0 & $0 \%$ & 0 & $0 \%$ \\
\hline Misuse of past future tense & 11 & $3 \%$ & 3 & $4 \%$ \\
\hline Misuse of past future perfect tense & 1 & $0 \%$ & 0 & $0 \%$ \\
\hline $\begin{array}{l}\text { Misuse of past future progressive } \\
\text { tense }\end{array}$ & 0 & $0 \%$ & 1 & $1 \%$ \\
\hline $\begin{array}{l}\text { Misuse of past future perfect } \\
\text { progressive tense }\end{array}$ & 0 & $0 \%$ & 0 & $0 \%$ \\
\hline Total & 395 & $100 \%$ & 75 & $100 \%$ \\
\hline
\end{tabular}

On the whole, the sixteen categories of tense errors distribute more evenly in free writings and the error rates of the same tense are different in CLEC and in free writings, which shows that under otherwise equal conditions the time limit can indeed affect the students' performance on tense. The detailed descriptions are as follows:

1). Although the simple present tense and the simple past tense are still the most frequently misused tenses in free writings, the error rates of them drop near double the frequency in CLEC, with the simple past tense error rate a bit higher than simple present tense error rate in free writing, which is just opposite in ST3. The results we got from the comparison show that the error rates of the simple present tense and simple past tense are indeed affected by the limit of time. The simple present tense and the simple past tense are the most basic tenses in English tense system, which are used to express the action or state in the present time and in the past and are also among the first learnt tenses by Chinese learners when they begin to learn English, so it is not surprising that the two tenses are misused most frequently in both CLEC and free writing. What's more, simple present tense and simple past tense are most frequently misused as each other's substitution. From the present study, we find that simple present tense is greatly overused as a substitution of simple past tense and almost of every correct tense. 
Since Chinese learners get familiar with those two tenses at the very early stage of learning English, we are supposed to have the ability to use them correctly in the composition, which is just the exact opposite case in CLEC. One of the reasons is that the students' compositions are directly taken from the test site where the students inevitably suffer from time stress and test anxiety, which results in poor performance of the tense usage. Another reason is that students try to avoid using the unfamiliar language points and complicated tense structures in limited time in order to assure their success in language using, which is known as avoidance strategy in Second Language Acquisition. Using the avoidance strategy sometimes can indeed avoid error happening to some extent, but overusing avoidance strategies in the learning process will exert negative influence on developing learners' language performance abilities in the long round. Furthermore, time limit urges the students to rush through the composition and they always have no time to do the proof-reading, which results in high error rate. Given the students more time to chew over the diversity of tenses, they are quite able to eliminate such errors in the compositions by themselves.

2). The third most frequently misused tense in free writing is past perfect tense (13), with the percentage of $17 \%$, while the percentage in ST3 is 3\%, which is greatly less than $17 \%$. Similarly, the percentage of misused present perfect progressive tense (1\%) in ST3 is also below the percentage in free writing (5\%), which ranks the forth in free writing. It seems as if the students' proficiencies of IMFEC are lower than the students of ST3 at the first sight, simply for they have made more errors, but the fact that the basic tenses like simple present tense decrease greatly while other tenses like past perfect tense increase drags us to reconsider the conclusion, which probably indicates that students begin to take time thinking which tense is more proper and consciously choosing the more complicated tense to increase diversity of the composition. In this sense, more time means more binds of tense expression; in another sense, more binds of tense expressions mean more errors, which also shows the students' master of the tense formula is not skilled from the other side.

3). The error rates of misuse of present perfect tense, misuse of past progressive tense, misuse of future tense and misuse of past future tense are close both in ST3 and in free writing, with the percentage $4 \%, 1 \%, 3 \%$ and $4 \%$ correspondingly in free writing. From the table, we can see students tend to make the same errors in the similar small error rate regardless of the time limit which probably shows that students have a good command of those tenses comparatively and they are consistent in using certain tense expressions even sometimes those expressions are wrong. In this group, misuse of present perfect tense and misuse of past future tense merit our close attention. For present perfect tense, it is always mistakenly substituted for by other regular types of tenses, among which the most confusing tense is the simple past tense. Likewise, Chinese learners are more likely to use the present perfect tense where the simple past tense should be used; next comes the past perfect tense; after that comes the simple present tense, that is to say, present perfect tense is prone to be more problematic in tense choice errors than in the tense form errors. To put it differently, Chinese learners always waver in choosing the proper tense formula in context. Generally speaking, those choice errors are due to the differences of the expression of temporality between Chinese and English as well as the violation of the meaning of present perfect tense.

As for past future tense, there are always more errors occurring in tense form than in tense choice. From the re-categorization and statistics, we have found future tense is most frequently misspelled as the form of past future tense. In brief, Chinese learners incline to use "would" instead of "will", which can be considered as the example of interference of target language. In the past future sphere, "would" has the meaning of predictability. What's more, "would" also means willingness, intention and insistence or it can be marked for politeness or tentativeness. Another important use of "would" is to convey hypothetical meaning to denote something contrary to the speaker's assumption (Li Ji'an, 2000:174). As "would" has so many meanings, students may apply it wrongly into a category he has taken for granted, as is shown by the following example:

1). The teacher considers it busy for them to study and gives [cc3,-3] them some time to play. like these [pp2,1-], the teacher would like teaching and the student [vp6,-] have [vp3,-] interest in studying [wd3,-].

2). General [wd2,-1] speaking, after the study in [wd3,-2] the school, every student would [vp6,s-] go to the society to contribute himself to his country.

3). In my opinion First [fm3,-] I would [vp6,s-] study in our college and learn

[cc3,-2] more knowledges [np5,-]. Second, I would join [wd4,-3] the social activities so I can get to know the World [fm3,-3] Outside the Campus. (Cited from CLEC)

Because of learners' incorrect notions of an L2 item, the error occurs by direct reference to the target language, which reflects the learner's transitional competence and appears more at intermediate and more advanced levels (Littlewood, 1984: 22-23). In Littlewood's view, there are probably two main reasons behind this kind of error. The 
first is that learners do not learn an exception to the general rule which does not apply to a particular item. The second is we wrongly apply an item into a category we have taken for granted (1984: 23).

4) As regards past perfect progressive tense, future progressive tense, future perfect tense, future perfect progressive tense, past future perfect tense, past future progressive tense and past future perfect progressive tense, Chinese students tend to use them infrequently. Through careful observation of the students' composition, we've found that there are almost no errors of past perfect progressive tense, future progressive tense, future perfect tense and past future progressive tense in ST3, which does not only mean less errors, but also means that students seldom use those tenses or even never use them as native speakers do. But in free writings, those tense errors appear with the percentage of $4 \%, 3 \%, 3 \%$ and $1 \%$ respectively, which implies free time gives the students plenty of time to think over the proper tense expressions and stimulates them to take the initiative in choosing the more difficult tense expressions. For future perfect progressive tense, past future perfect tense and past future perfect progressive tense, there are even no occurrences in both ST3 and in free writing, which clearly shows Chinese learners are not familiar with those tenses and need specific guidance from the teachers.

As whole, it can be concluded that Chinese college students (Freshmen of non-English majors) overuse the simple present tense and the simple past tense, considerably more frequently than other tenses, while they underuse all kinds of future tenses except the future tense and the past future tense, which shows that Chinese learners' acquisition of the tenses is not as good as they are expected to and needs further guidance.

\section{Conclusion}

This paper investigates the characteristics of Chinese EFL learners' tense errors based on the data from CLEC. By adopting EA method, the learners' most frequently misused tense errors are firstly figured out. Then the results for the investigation into the characteristics of Chinese EFL learners' tense errors are presented.

\subsection{Analysis of Error Sources}

In the above parts, the specific reasons of each error type were discussed immediately after the presentation of the data. In this part, we try to diagnose the errors of misuse of verbs by presenting three major causes - mother tongue influence, target language influence and cognitive causes.

\subsubsection{Mother Tongue Influence: Interlingual Errors}

Interlingual errors or interference errors can be directly traced back to the mother tongue. Although there is inconclusive over the definition of interference, Dulay and Burt (1982: 101-102) define interference as the automatic transfer, due to habit, of the surface structure of the first language onto the surface of the target language. In order to make sense of a new expression, the learner makes use of his previous mother tongue experience to learn a new language, which will cause many misuses.

To Chinese learners, Gui Shichun (Gui, 2005) points out that Chinese has a great influence on their errors, including the tense errors, disagreement and so on. Yu Liming (2004: 136-140) claims that up to $70 \%$ of the errors made in students' CET4 and CET 6 writings can be traced back to the L1 transfer. He also claims that the system of tense and aspect in Chinese is totally different from that in English, so Chinese students will unavoidably make mistakes because of that difference. Therefore, it is difficult for CLL to learn grammars of verb phrase in English because English and Chinese are not corresponding, which will unavoidably interfere with the target-language learning.

The verb errors found in the sample writings of CLEC and free writings suggest that many verb errors exist with the cause of influence of their mother language. That is to say, the erroneous sentences do not make sense in English, but if translated into Chinese, they really do. In the following there are some examples, from which the sign of the mother influence can been clearly seen:

1) 1. After we graduate from colleges, the ways that we get to know the world outside the campus are many. We can read the newspaper, watch TV, listen [vp1, -1] radio and etc (From CLEC).

2) 2. On the other hand college students we learned [cc4,2-] will soon got [vp9,2-] into society, it is an [np7,-] well-known book and everyone have [vp3, 1-] almost read or hear [vp4,4-] [vp1,-] It (From CLEC).

3) 3. When we graduated from the high school and enter [vp6, s-] the college, our task of study becomes easier (From free writing).

Example 1 shows the great influence of Chinese meaning on the verb class judged in English, while Example 2 
and 3 show the influence of Chinese syntactic grammar on English syntax, especially on the verb inflections in terms of person, number and tense. Such kinds of errors are scattered widely in the students' compositions both in CLEC and in free writings.

Since Chinese and English are not corresponding, it is not difficult to understand why there are so many differences in every language facet. The author has also talked with some subjects about the reasons why they made such kinds of verb errors. Not a small part of them said they felt they could only think and write in Chinese first, then translate their expressions into English. So it is not surprising why there are so many errors look like Chinese expressions, such as "listen radio". Similarly, students commit grammar errors because a grammatical marker of verb phrase does not exist in the L1. For example, Chinese does not differentiate persons or numbers at all, which results in the occurrence of "everyone have..." Moreover, Chinese does not use inflectional means to mark tense at all. Instead, they depend on vocabulary to express the concept of past and present, and grammar is not related to this process at all.

The present study also shows that among all the types of misuse of tenses, present tense is the most frequently misused tense, and it is most frequently misused as a substitution of past tense in almost every sub-corpus in CLEC. According to Shaughnessy (1977: 94), the inflections of the "regular" verbs (-ed, -d, -t) are easily lost in both oral and written form, especially where a speaker's mother tongue has given him no or limited experience with such an inflection.

\subsubsection{Target Language Influence: Intralingual Errors}

One of the major contributions of error analysis is its recognition of sources of error that beyond just interlingual errors in learning a second language. Researchers have found that the early stages of language learning are characterized by a predominance of interlingual interference, but once learners have begun to acquire parts of the new system, more and more intralingual transfer --- generalization within the target language --- is manifested.

Target language influence in this dissertation mainly refers to learners' incorrect notions of an L2 item which can be explained by direct reference to the target language, which will result in intralingual Errors. Intralingual errors reflect the learner's competence at a particular stage and illustrate some of the general characteristics of language acquisition. In some learners they represent final grammatical competence; in others they may be indications of transitional competence (Richards, 1985: 30).

Target language influence is mainly manifested by overgeneralization and undergenralization, etc. According to Richards (1985: 48), overgeneralization "covers instances where learners create a deviant structure on the basis of their experience of other structures in the target language". Undergeneralization is the converse of overgeneralization, which can also be labeled as incomplete rule application. The feature of this strategy is that the learner fails to fully develop a rule and tends to apply it incompletely.

The errors induced by them can be found in each sub-corpus and in free writings, which indicate that L2 learners are usually unconsciously concerned about the improper use of L2 rules, when they have no sufficient second language knowledge to express their ideas. The following examples from data might be evidence to show the interference of target language:

1) If we meet with [vp1,2-] foreigners, we would be able to communicate with them if we knew foreign languages (From free writing).

2) There are birds, spring flowers, fresh air and so on, which satisfies [vp3 -] your walk. If you walk on the way of a small country, when you see a smoke [np5,-] from a wood stove, you will feel you were [vp6,-] at home, yes or no (From CLEC).

3) How do we get to know the world outside the campus? First, I think, I would [vp6,s-] have [wd3,-5] a full use of these such as magagizes [fml,-], newspapers, TV, radios and so on (From CLEC).

4) How I wish I can [vp6,s-] grasp several foreign languages after graduation then I will become a tourist traveling all over the world (From free writing).

Over-generalization errors occur when a deviant structure is produced by the learner on the basis of his experience of other structures in the target language. In example 1, the learner generalizes the rule that "meet" must be followed by preposition "with" when its object is "difficulty", "barrier", etc., but when its object is a person, no preposition is needed. In example 2 and 3, there are similar cases. In subject-verb agreement, singular form of subject requires inflections of the predicate in the present tense, but the learner fails to recognize the point. In 3 , Chinese Learners incline to use "would" instead of "will", which is also caused by interference of target language. 
Since "would" not only has the meaning of predictability but also means willingness, intention and insistence or it can be marked for politeness or tentativeness (Li Ji'an 2000:174), students often use the word wrongly according to his partial understanding. In example 4, subjunctive mood is used to show very slim possibility, so the structure "wish that + subject of the clause + would/could + verb" should be used to express a future dream. The learner knows the subjunctive mood, but he fails to know "could" should be used here to replace "can", which is a typical example of incomplete application of rules.

\subsubsection{Cognitive Causes}

According to Cognitive theory, second-language learning, like any other complex cognitive skill, involves the gradual integration of sub-skills as controlled processes initially predominate and then become automatic. Thus the initial stages of learning involve the slow development of skills and the gradual elimination of errors as the learner attempts to automatize aspects of performance. In later phases, there is continual restructuring as learners shift their internal representations (Barry McLaughlin, 1987, Cited in Zhang, 2001: 67).

For EFL learners, the interlanguage system would be incomplete and all kinds of verb errors would be inevitable unless the proper EFL concept system is constructed with reference to the L1 instead of depending on the L1 concept. With CLL's English proficiency level increasing, their verb error rate decreases significantly, which shows the verb acquisition develops with the students' attempts to automatize their aspects of performance. The present study finds that sometimes CLL attempt to use complex sentence structures by means of coordination and subordination, which often leads them into confusion of syntactic options. The fact that the student who in one sentence writes correctly will use the wrong form in another sentence clearly shows the student's gradual development that will become automatic finally (Zhou, 2008). The following sentences can be seen as such examples:

1) We will walk into society and serve [vpl, s-] for society. If we get to know the world outside the campus, we will be able to serve society better (From CLEC).

2) Mother's kiss is so sweet that it encourage [vp3, -] me to face difficulty [fml,-] bravely. Mother's kiss is so warm that it become [vp3,-] the energy source [wd3,-] of my progress (From CLEC).

3) During the course of doing it again and again, we mastered [vp6,-s] it and make a rapid progress. This practice what [wd3,1-] we took [ vp6 -s] makes perfect in the end. For example, when we do some cooking, we must master the way of cooking perfectly, so [wd5,-s] we cooked [vp6,-s] a very good dinner (From CLEC).

\subsection{Implications of the Research}

The statistical data of the present study provide some empirical evidence to the present situation of verb errors of Chinese learners, which will have some implications for L2 pedagogy, which can help Chinese learners explore how to make progress in a purposeful way and help English teachers re-adjust their teaching focus and methods. The concrete suggestions for L2 pedagogy are listed as follows:

For the vp6 teaching and learning, English instructors should spare no efforts to tell students the differences between English temporal system and Chinese temporal system so that Chinese English learners will feel easier to avoid the negative transfer of Chinese by establishing a deictic center when producing English sentences. It should also be noted that although CLL did not commit many errors in all the future tenses except simple future tense and past future tense, English teachers should not be misled into thinking that these tense errors are unimportant just because they occur less frequently, for the students may avoid using them because they are unfamiliar with them. In addition, Chinese students should be more aware of the adverbials of time which restrict the forms of verbs. Teachers can design some writing tasks that can help students to use the tense on correct occasions. The variety of topics should be taken into account because the topic will restrict students' use of the tense to some extent and a wide variety of topics will provide students with enough room to practise different types of tenses.

However, theory separated from practice would be water without source or a tree without a root. It is believed that writing is learnt mainly through writing in quantity, not simply through teaching. Only by constantly practising and organically combining writing with other skills, especially with reading, will students be able to develop their writing ability little by little, just as the proverb goes, "practice makes perfect". 


\section{References}

Bo, Bing. (2003). New English Grammar. Beijing: World Affairs Press.

Brooks, N. (1960). Language and Language Learning. New York: Harcourt Brace and World.

Corder, S. P. (1967). The Significance of Learners' Error. International Review of Applied Linguistics, 161-169.

Corder, S. P. (1974). Error analysis. In Allen and Corder, eds. Applied Linguistics.

Dulay, H., \& Burt, M. (1974a). Errors and strategies in child second language acquisition. TESOL Quarterly, 8, 129-136. http://dx.doi.org/10.2307/3585536

Dulay, H., \& M. Burt. (1974b). You can't learn without goofing. In J. C. Richards, ed. Error Analysis --- Perspectives on Second Language Acquisition. London: Longman, 95-124.

Dulay, H., M. Burt \& S. Krashen. (1982). Language Two. New York: Oxford University Press.

Gui, Shichun, \& Yang, Huizhong. (2005). Chinese Learner English Corpus (computer disk). Shanghai: Shanghai Foreign Language Education Press.

Li, Ji'an. (2000). Modern English Grammar. Beijing: Foreign Language Teaching and Research Press.

Littlewood, W. (1984). Foreign and Second Language Learning. Cambridge: Cambridge University Press.

Lyons, J. (1977). Semantics. Cambridge: Cambridge University Press.

Net.1. Tense. (2010). Retrieved January 21, 2012, from http://en.wikipedia.org/wiki/Tense

Palmer, F. R. (1965). A Linguistic Study of the English Verb. London: Longman.

$\mathrm{Pu}$, Jianzhong. (2000). A Survey of Chinese Learners' Use of English Verbs in Grammatical and Lexical Patterns. Modern Foreign Languages (quarterly), 1, 24-44.

Richards, J. (1974). Error Analysis. London: Longman.

Richards, Jack C. (1985). The Context of Language Teaching. Cambridge: Cambridge University Press.

Shaughnessy, Mina P. (1977). Errors and Expectations. New York: Oxford University Press.

Yang, Huizhong. (2002). An introduction to Corpus Linguistics. Shanghai: Shanghai Foreign Education Press.

Yu, Liming. (2004). Language Transfer and Second Language Acquisition: Review, Reflection and Research. Shanghai: Shanghai Foreign Language Education Express.

Zhang, Xiaolan. (2004). Error Analysis of English Writing by English Majors and its Implications. Journal of Sichuan International Studies University, 2, 152-155.

Zhou, Wenfang. (2008). A Corpus-based Study of Misuse of Tenses by Chinese English Learners. Unpublished PhD thesis, Shanghai Normal University. 